\title{
Gênero, saúde reprodutiva e vida cotidiana em uma experiência de pesquisa-ação com jovens da Maré, Rio de Janeiro*
}

Regina Simões Barbosa ${ }^{1}$

Karen Giffin ${ }^{2}$

BARBOSA, R.S.; GIFFIN, K. Survey and action on gender, reproductive health and daily life with youngsters in Maré, Rio de Janeiro. Interface - Comunic., Saúde, Educ., v.11, n.23, p.549-67, set/dez 2007.

This article presents a conceptualization of action research which articulates Paulo Freire's pedagogy with feminist methods of consciousness-raising. It aims to contribute to wider comprehension of the problems which affect Brazilian youth by presenting questions of daily life as they are experienced by young men and women who live in the Complexo da Maré, an extensive area of favelas in the city of Rio de Janeiro. These questions were identified through a process of action research which articulated young people in consciousness-raising groups that adopted the 'generating themes' of gender identity, sexuality and reproductive health. These themes were connected to other significant questions which gradually emerged from the wider sociocultural and political dimensions that affect the lives of young people, particularly those who live in contexts of poverty, violence and exclusion from basic rights. An attempt is made to conceptually and empirically consolidate an outlook that transversalizes gender in social class and a paradigm of knowledge that legitimates new subjects of knowledge who are engaged in transformative social action.

KEY WORDS: Youth. Reprodutive health. Research-action. Citizenship.

O artigo apresenta uma conceituação da pesquisa-ação que articula a pedagogia de Paulo Freire e a proposta reflexiva e prática do movimento de mulheres. Pretende contribuir para ampliar a compreensão dos problemas que afetam a juventude brasileira com base nas questões de vida e saúde vivenciadas por jovens - rapazes e moças - moradores de uma área favelada da cidade do Rio de Janeiro. Estas questões foram captadas por meio de um projeto de pesquisa-ação que aglutinou jovens em grupos de reflexão-ação que adotavam, como temas geradores, a identidade de gênero, a sexualidade e a saúde reprodutiva. Esses temas iam gradativamente se conectando a outras questões significativas que emergiram das dimensões socioculturais e políticas mais amplas que afetam a vida dos jovens, particularmente daqueles que vivem em contextos de pobreza, violência e exclusão de direitos. Buscou-se consolidar, conceitual e empiricamente, o enfoque que transversaliza gênero na classe social e o paradigma de conhecimento que legitima um novo sujeito de conhecimento engajado na ação transformadora.

PALAVRAS-CHAVE: Juventude. Saúde reprodutiva. Pesquisa-ação. Cidadania.

\footnotetext{
* Projeto desenvolvido entre 2002 e 2004, pelo Laboratório de Gênero e Saúde do Núcleo de Estudos de Saúde Coletiva/NESC, UFRJ, e Núcleo de Gênero e Saúde, Escola Nacional de Saúde Pública/ENSP, Fiocruz, com apoio da Fundação Ford e CNPq. Equipe de campo: Lucia Baptista (coordenadora de campo), Luis dos Santos Costa, Cristina Cavalcanti (pesquisadora), Baldinir Bezerra da Silva, Miriam Andrade Silva Afonso e Sinésio Jefferson Andrade Silva.

${ }^{1}$ Psicóloga; doutora em Saúde Pública; professora, Instituto de Estudos em Saúde Coletiva, Departamento de Medicina Preventiva, Faculdade de Medicina, Universidade Federal do Rio de Janeiro, RJ. <regina@iesc.ufrj.br>

${ }^{2}$ Socióloga; pós-doutora em Sociologia; professora, departamento de Ciências Sociais, Escola Nacional de Saúde Pública Sérgio Arouca, Fundação Oswaldo Cruz, Rio de Janeiro, RJ. <karengi@ensp.fiocruz.br>
}

${ }^{1}$ Praça Jorge Machado Moreira (Praça da Prefeitura), nº 100 


\section{Introdução}

Este artigo pretende contribuir para ampliar a compreensão dos problemas que afetam a juventude brasileira por meio da análise das questões de vida $e$ saúde vivenciadas por jovens - rapazes e moças - que vivem no Complexo da Maré, área favelada situada na Zona Norte da cidade do Rio de Janeiro. Essas questões foram captadas e visibilizadas por intermédio de um projeto de pesquisa-ação voltado para a população jovem que reside nessa imensa $e$ problemática região do Rio de Janeiro ${ }^{3}$.

Os temas geradores que deflagraram o processo de reflexão-ação entre os jovens foram as identidades de gênero, a sexualidade e a saúde reprodutiva. Porém, no enfoque de pesquisa-ação aqui adotado, esses temas foram paulatinamente se conectando a outros, que emergiram das dimensões socioculturais e políticas mais amplas que afetam a vida dos jovens, particularmente daqueles que vivem em contextos de pobreza, violência $e$ exclusão de direitos de cidadania. Buscou-se consolidar, conceitual $e$ empiricamente, a transversalidade do gênero na classe social e raça/etnia, numa perspectiva geracional.

\section{Conceitos e metodologia: gênero e pesquisa-ação}

O objetivo do projeto foi promover, por meio da perspectiva de gênero, a saúde sexual e reprodutiva de jovens que vivem em contextos de pobreza. Estes foram os "temas geradores" que deflagraram - e se entrelaçaram a - outros temas trazidos pelos próprios jovens e relacionados às difíceis questões que afetam suas vidas e de suas comunidades.

Tal enfoque - e tal percurso - advém de uma compreensão da dimensão de gênero que, ao invés de tomá-lo como uma instância que determina, por si só, diferenciais de vulnerabilidades entre homens e mulheres, o entrelaça $e o$ dialetiza com outras identidades sociais, especialmente aquelas referidas a classe social, raça/etnia e geração (Giffin, 2002; Simões Barbosa, 2001; Kergoat, 1996; Saffioti, 1992). Esta interpretação, relacional e transversal, advoga que o gênero se constitui, se amalgama e se concretiza em determinadas circunstâncias materiais - econômicas, sociais, políticas, culturais e geracionais. Portanto, refuta-se a existência de "Homens" $e$ "Mulheres" tomados como categorias universais e propõe-se a analisar homens e mulheres situados em condições concretas de vida relacionadas, sobretudo, às suas inserções por classe social, raça/etnia e geração4.

Tendo em vista esta perspectiva, como podemos nos restringir ao debate sobre identidades de gênero, sexualidade e saúde reprodutiva sem associar e interligar essas questões aos direitos a uma vida digna, ou sem questionar uma sociedade que exclui esse contingente da população jovem do acesso a direitos elementares, como o "direito de ir e vir"? ${ }^{5}$ Como despertar a auto-estima, e o correlato desejo de se proteger das DST/AIDS, entre jovens que, ao pleitearem um emprego, não podem declarar seus endereços de moradia sob pena de serem sumariamente descartados? Como falar de sexo, amor e cuidado (auto e mútuo) num contexto de violência social em que forças institucionais e "paralelas" torturam e matam jovens por motivos absolutamente fúteis?

\author{
3 O Projeto de Pesquisa \\ "Jovens, Saúde e Vida \\ Cotidiana: uma \\ proposta de pesquisa- \\ ação", foi julgado $e$ \\ aprovado para \\ execução pelo Comitê \\ de Ética em Pesquisa \\ do NESC/UFRJ.
}

\author{
${ }^{4}$ As questões \\ associadas à \\ discriminação racial \\ emergiram no campo e \\ foram trabalhadas nos \\ grupos, mas não foram \\ incorporadas enquanto \\ dimensão de análise, \\ devido às nossas \\ limitações ideológicas \\ nesse campo.
}

\footnotetext{
${ }^{5}$ Qualquer jovem da Maré pode ser sumária e friamente assassinado pelo simples fato de residir em determinada localidade e circular em comunidade vizinha controlada por uma facção inimiga.
} 
A pesquisa-ação (PA), por seu lado, filia-se a uma vertente epistemológica e metodológica que parte do questionamento radical do positivismo, paradigma de conhecimento que aspira à objetividade, neutralidade e universalidade. Apesar das polêmicas que envolvem este campo (Hollanda, 1993), $e$ concordando com Reason (1994), situamos a pesquisa-ação como "pesquisa do novo paradigma", onde a produção de conhecimento está intrinsecamente conectada à construção do sujeito do conhecimento e à ação transformadora. Afinal, uma proposta epistemológica, conceitual e metodológica que advoga a participação ativa, enquanto sujeitos do conhecimento, daqueles que, tradicionalmente, são tomados como "objetos", coloca-se em outra perspectiva no que se refere ao que é o conhecimento (sua natureza), quem pode produzi-lo (sujeito de conhecimento) e com que finalidade (reproduzir a sociedade atual ou transformá-la). Portanto, a pesquisa-ação, tal como aqui concebida, pretende gerar, com e pelos sujeitos pesquisados, novos conhecimentos $e$ ações coletivas que buscam transformar uma sociedade profundamente marcada pelas desigualdades e injustiças sociais.

O modelo de PA desenvolvido por nosso projeto é caudatário de duas vertentes que detêm profundas afinidades conceituais, pedagógicas $e$ metodológicas: a pedagogia de Paulo Freire e a proposta educativa praticada pelo movimento de mulheres.

A primeira vertente parte do preceito de que 'educar não é transferir conhecimentos', mas uma relação de troca, permanente diálogo e profundo respeito entre educador e educando, em que ambos ensinam e aprendem. Neste sentido, relativiza a importância do saber formal e valoriza o saber popular e os conhecimentos adquiridos nas experiências práticas da vida cotidiana. Nesta perspectiva, a própria apreensão de conhecimentos formais está conectada a processos que articulam a racionalidade às dimensões afetivas, culturais, morais, coletivas e históricas. Assim, ensinar pressupõe uma convivência amorosa e uma postura curiosa e aberta dos educadores para com os educandos, e, ao mesmo tempo, uma atitude problematizadora que os instiga a se assumirem enquanto sujeitos sociohistóricos do ato de conhecer (Freire, 1996).

A finalidade última da educação, na visão freireana, é a libertação de todos os oprimidos e explorados do sofrimento, da discriminação e da opressão que advêm das iniqüidades e injustiças sociais, entre as quais as desigualdades de gênero.

A consciência das mulheres sobre sua opressão é antiga na história humana. Porém, é somente na década de 1960 que se reconstitui um movimento social de mulheres com o propósito de lutar por relações igualitárias entre os gêneros. Neste processo, emerge a necessidade de formulação teórica que explique a opressão feminina e fundamente as bases das transformações sociais e culturais almejadas pelas mulheres.

Assim, o conceito de gênero vem se contrapor à explicação que justifica o papel de inferioridade social da mulher em função de seu papel na reprodução biológica, denunciando que este lugar de submissão tem causas históricas, políticas, sociais, econômicas e culturais definidas e pode ser, portanto, transformado.

Epistemologicamente falando, os estudos de gênero emergem da experiência de reflexão coletiva de mulheres sobre seus corpos, emoções e vivências 
enquanto mulheres. Essa trajetória, que vai do concreto para o abstrato, do corpo para a razão, do afeto para as idéias, levou as mulheres a questionarem, entre outros pilares da ciência ocidental, a própria racionalidade dicotômica do conhecimento que, ao separar razão e emoção, teoria e prática, sujeito e objeto de conhecimento, apresenta uma ciência neutra e descomprometida com a transformação social.

Os grupos de reflexão que deram origem ao movimento feminista são uma expressão do processo de contestação da ordem vigente e da possibilidade de reconstituição da auto-identidade. Nesses grupos, o compartilhamento coletivo das experiências privadas permitiu a desnaturalização das ideologias de gênero que, historicamente, encobrem a construção social das identidades masculina e feminina e, assim, a reprodução de hierarquias sociais. A percepção de que a própria auto-identidade é coletivamente construída e, portanto, passível de transformação coletiva, foi expressa no lema 'o pessoal é político' e na nova auto-identidade política e científica das mulheres (Giffin, 2006, 1999, 1995).

No campo das práticas educativas, as propostas do feminismo e da pedagogia da libertação freireana, na medida em que representam pontos de vista de explorados e oprimidos, guardam profundas afinidades. Em última análise, ambas almejam a construção de caminhos que apontem para a superação das desigualdades sociais - o que inclui as relações entre homens $e$ mulheres - na direção de um mundo justo, fraterno e solidário (Simões Barbosa, 2001a).

\section{O desenho metodológico do projeto: grupos de reflexão de gênero}

Com base no referencial apresentado, $e$ apoiados em nossas experiências anteriores ${ }^{6}$, desenvolvemos e implementamos uma proposta de reflexão-ação em grupos de reflexão de gênero (GRG) direcionados para os jovens da Maré.

A proposta consistiu, primeiramente, no recrutamento preferencial (mas não exclusivo) de jovens que já atuassem como "agentes sociais" em suas comunidades, tendo por objetivos potencializar o papel de "facilitador de reflexões" desses jovens e constituir e/ou fortalecer redes sociais de jovens que tivessem como eixo a luta por direitos de cidadania para a juventude brasileira.

Após a constituição inicial de um grupo de jovens, esses eram convidados a escolher, já em processo de grupalização, os temas que consideravam mais significativos para si e suas coletividades. Os temas eram escolhidos em meio a intensos debates, reflexões e vivências, coordenados pelos facilitadores da equipe. Iniciava-se, assim, um processo de várias etapas que, para fins didáticos, podemos caracterizar como: estranhamento, problematização $e$ desnaturalização do cotidiano, reflexão crítica e definição coletiva de ações/atuações.

As oficinas, mais que um conjunto de atividades lúdicas que incluíam jogos, dinâmicas e outros exercícios grupais, pretendiam promover o crescimento do grupo, captando e trabalhando reflexivamente suas demandas e necessidades, desenvolvendo a auto-estima, habilidade comunicativa e capacidade de realização de ações, de curto e médio prazos, voltadas para a coletividade.

\footnotetext{
${ }^{6}$ Projetos de pesquisa "Mulheres de Periferia Urbana: construindo um modelo de intervenção para a prevenção das DST/ AIDS” (NESC/UFRJ, apoio PN DST/AIDS MS) e "Participação Masculina na Esfera da Saúde Reprodutiva: uma proposta de pesquisa-ação" (NESC/ UFRJ e ENSP/Fiocruz, apoio Fundações Ford e MacArthur); ver também Valladares et al., 1987.
} 
Os jovens participantes do projeto reconheceram amplamente que a metodologia reflexiva, por eles vivenciada e, posteriormente, por eles incorporada na atuação com outros grupos comunitários, era muito diferenciada do modelo educativo tradicional. Como alguns declararam, "fazer oficina", "promover reflexão" é bem diferente de "dar palestra" ou ensinar aos outros o que é "correto", tal como na perspectiva normativa tradicional. Alguns depoimentos sinalizam quanto esses jovens podem se transformar, de objetos, em sujeitos da reflexão/ação transformadora:

... em diversas oficinas [de outros projetos] em que participei, nenhuma delas foi apresentada ou ministrada por pessoas da mesma faixa etária que eu, que entendesse e falasse a linguagem dos jovens presentes. Apesar de expor muito bem as informações, eu não sentia que falavam diretamente comigo, pois o assunto mais abordado, que é que temos que usar preservativo, vinha sempre como imposição e não por uma opção de sexo seguro.

... no projeto $X$ [outro projeto social da Maré], o grupo foi capacitado pra ser multiplicador. Nosso trabalho era repetir o que tínhamos aprendido.

... eu acho que isso é que faz a diferença de vocês [projeto de pesquisaação] em relação aos outros grupos. Estou descobrindo aqui que não basta dar o recado, tem que fazer pensar, relaxar, refletir. Nos outros grupos, as pessoas ficam falando o tempo todo, e a gente fica só ouvindo. Eu quero aprender a fazer oficina, não é aula.

...aqui eu aprendi muita coisa, e já repito com meu grupo as reflexões que a gente faz aqui.

Particularmente no trabalho com jovens, é de fundamental importância considerar os campos da cultura, arte e das expressões criativas para a construção de pontes entre o saber formal e o saber prático e a elaboração coletiva de valores éticos que fortaleçam a noção e o sentimento de pertencimento social e cidadania (Simões Barbosa \& Giffin, 2005).

A imaginação, o pensamento $e$ as sensações dos jovens foram trabalhados por meio de diversas formas de expressão criativa: desenho, recorte $e$ colagem, som, movimentos, expressão corporal, música, dança, dramatizações etc. Os trabalhos corporais facilitaram não só a interação do grupo como, também, a expressão de sentimentos. A utilização de jogos teatrais $e$ exercícios corporais na maioria das oficinas foi o recurso mais eficaz para lidar com as complexas questões trazidas pelos jovens. Se, por um lado, alguns deles se sobressaíam pela agitação - falando muito, monopolizando as atenções - outros se caracterizavam pelo desânimo, pela dificuldade de concentração, por um ou outro olhar distante, descrente. Esse tipo de postura parece estar associado a um sentimento de impotência diante da realidade vivida e à desesperança em relação a qualquer possibilidade de mudança. Freire já alertava para uma ideologia fatalista, imobilizante, típica do discurso neoliberal, que insiste em convencer-nos de que nada podemos 
contra a realidade social que, de histórica e cultural, passa a ser vista como "quase natural" (Freire,1996, p.21).

Dessa forma, o trabalho educativo-reflexivo foi encaminhado no sentido de possibilitar o estranhamento $e$ a problematização de conceitos $e$ valores alicerçados numa visão conformista da realidade. O levantamento de dados que alguns grupos elaboraram e realizaram com outros jovens da comunidade atuou como um exercício de expansão da capacidade de ver o mundo à sua volta $e$ perceber os espaços em que podem estar atuando de forma crítica $e$ transformadora. Ainda segundo Freire, faz-se necessário que o indivíduo estabeleça esse contato com sua situação existencial, concreta, presente e a estabeleça como problema que, por sua vez, o desafia e, assim, lhe exige resposta, não só no nível intelectual, mas também no nível de ação (Freire, 1981).

Desencadeadas pelas vivências, as reflexões coletivas em torno de diferentes pontos de vista, no intercâmbio de experiências dentro do grupo, favoreceram a comunicação entre os jovens e entre esses e seu entorno sociofamiliar: saber ouvir, saber falar, defender posições e buscar consensos são aprendizados que tendem a ser reproduzidos no convívio familiar e comunitário dos jovens, como reconhecido por muitos participantes:

... eu mudei muito desde que comecei a freqüentar essas reuniões. Estou mais responsável. As pessoas notam.

... o que mudou foi na minha vida familiar. Antes eu só escutava, e eles falavam, falavam ... Agora eu falo também. Descobri que minha opinião tem valor.

...eu, como os outros colegas, aprendi a ouvir mais os outros, a fazer as pessoas pensar a respeito dos problemas da sociedade: violência, tráfico, desigualdade social ...ver que, se cada um fizer a sua parte...o país, quem sabe o mundo, pode ser bem melhor.

...entendi que esse trabalho ajuda a gente a se comunicar melhor. Comunicação é muito importante.

O projeto previu, inicialmente, a constituição de um grupo de jovens por semestre, o que totalizaria, ao final de dois anos, quatro grupos (atuando de forma entrelaçada). O tempo de trabalho previsto para cada grupo era de cinco meses, totalizando cerca de vinte oficinas por grupo. Os encontros semanais tinham duração média de três horas, dependendo da disponibilidade do grupo e das condições locais. O término do grupo deveria ser, preferencialmente, marcado por um projeto de atuação individual e/ou grupal.

Foi previsto que cada grupo se incorporaria aos grupos subseqüentes, neles atuando como multiplicadores (com o acompanhamento dos facilitadores da equipe). Contudo, condições favoráveis e desfavoráveis influenciaram os rumos que o projeto tomou. No sentido favorável, constituímos, ao longo de dois anos, sete grupos, totalizando cerca de oitenta jovens, ultrapassando largamente a meta inicial. Esse fato nos revela o enorme interesse que propostas deste tipo 
despertam entre os jovens que vivem nesse contexto de tão escassas oportunidades de (auto)desenvolvimento. Considere-se que nosso projeto, ao contrário da maioria dos outros, não oferecia remuneração aos participantes. Como criticamente observou uma facilitadora de nossa equipe, também moradora da Maré, ao responder a uma dirigente de ONG local, que nos cobrou por não apresentarmos "produtos" culturais (em geral, performances artísticas) resultantes do projeto: "nós não temos 'produtos' para oferecer [no mercado cultural], nós produzimos 'consciência crítica'," algo não palpável e perceptível para olhares mais identificados com o consumo, que inclui uma certa "glamourização" da cultura da favela, tal como atualmente promovido pela indústria cultural cinematográfica e televisiva (Rede Globo, por exemplo).

No segundo aspecto, constatamos, muitas vezes impotentes, que alguns grupos se desorganizaram e/ou se dispersaram em função dos muitos e tensos momentos de confronto armado nas comunidades da Maré. Em alguns momentos mais críticos, alguns grupos pararam de se reunir. Em outros, a equipe conseguiu deslocar, temporariamente, as oficinas para o campus da UFRJ. Houve dois acontecimentos dramáticos que atingiram, direta e indiretamente, dois participantes do projeto: tanto a mãe quanto um dos rapazes de um dos grupos foram acidentalmente baleados. Esses fatos abalaram profundamente os jovens desses grupos, o que exigiu da equipe total empenho, carinho e solidariedade para que eles, revoltados com o mundo injusto $e$ violento que aí está, não abandonassem o projeto. Cabe lembrar que esses dramáticos fatos ocorreram após a criação, pelos jovens, do esquete "Maré, por que não?", em que procuravam significar positivamente a sua comunidade de pertencimento.

Em nossas discussões de equipe, avaliando relatos e resultados das reflexões dos grupos, ficou evidenciada a urgência da criação de ferramentas concretas para viabilizar uma outra política de segurança pública. Alguns depoimentos de jovens participantes dos grupos apontam e denunciam as graves questões vivenciadas pelos moradores da Maré, particularmente os mais jovens:

No outro dia, meu filho me pediu prá comprar uma arma prá ele brincar: [o
filho] 'Os meninos lá da rua tem, mãe' ... [a mãe] 'Arma machuca, meu filho' ...
[o filho] 'Machuca não, mãe ... Eles tão só brincando'... Na inocência, ele tava
falando dos guris que tavam na esquina, brincando com armas de verdade.
Como falar com ele sobre violência? Tem só quatro anos... E já tá fascinado
pelas armas, de olho nos meninos lá na esquina. É isso que ele vê do portão....

Este depoimento sinaliza quanto as identidades de gênero se constroem intimamente entrelaçadas aos contextos sociopolíticos em que os indivíduos vivem. Neste caso, vemos o fascínio que armas exercem sobre os meninos da favela, significando, simbolicamente, a constituição da identidade masculina hegemônica, associada à força e ao exercício do poder. Como se contrapor a essa situação quando outras oportunidades de auto-realização não estão dadas ou quando o ethos da masculinidade é cada vez mais reforçado nessa direção? (ver, por exemplo, Connell, 1995).

Neste sentido, os jovens do projeto expressaram ter consciência da situação que lhes "cassa" seus direitos de cidadania e reivindicaram, além de escola $e$ saúde, o direito de ir e vir, oportunidades culturais e de lazer: 
Deveria haver campeonatos ou incentivos para podermos mostrar nossa arte.

Mais esportes para as crianças, desconcentrando um pouco essas atividades da Vila Olímpica. ${ }^{7}$

Em decorrência desse cenário, tão desfavorável ao cultivo de posturas positivas, de mútua confiança e da solidariedade que impulsionam a ação coletiva, tivemos algumas perdas decorrentes de necessidades de sobrevivência básicas, tais como: busca de emprego para ajudar na renda familiar, falta de

7 Vila Olímpica da Maré, da Prefeitura do Rio de Janeiro. apoio familiar e, mesmo, falta de identificação com a proposta. Entretanto, nenhum dos motivos que definiram o afastamento de alguns participantes foi mais doloroso do que vê-los cooptados pelo esquema do narcotráfico - fato que fomos obrigados a assistir, impotentes, e que gerou, na equipe, doloroso sentimento de perda. Os participantes nos reportaram que, pelo menos, três dos jovens que se afastaram já estavam seguramente envolvidos com o narcotráfico. $O$ depoimento abaixo é revelador de algumas das questões implicadas nesta dramática (falta de) opção:

O F... não está mais vindo para o Projeto. Acho que ele mudou de turma. Problema de dinheiro. A família tá passando apertado. Acho que ele não segurou a onda. Eu tenho visto ele com os 'caras' na calçada.

Da criança que olha fascinada para os meninos armados à adesão ao narcotráfico, passam-se apenas alguns anos, em um período fundamental na formação da identidade individual e social dos indivíduos, tendo a identidade de gênero participação protagonista nesse processo.

Portanto, as questões de gênero, tais como aqui concebidas, estiveram perpassando todas as dimensões de vida dos jovens participantes do projeto, confirmando a oportunidade do enfoque transversal para o desvelamento e a compreensão da complexidade da constituição dos sujeitos sociais.

\section{Temas geradores e temas gerados por meio da reflexão-ação}

Como ocorreu em nossa pesquisa-ação com grupos de homens, o projeto a que este artigo se refere iniciou os grupos de jovens no processo reflexivo por intermédio dos temas gênero, sexualidade e saúde reprodutiva que, gradativamente, se agregavam a outros temas identificados e trazidos pelos participantes. Em determinado momento do processo, quando o grupo estava já "grupalizado", ou seja, já havia estabelecido um "contrato de convivência" que selava o acordo do grupo em torno de valores éticos e normas de respeito entre os integrantes, iniciava-se a escolha dos temas de interesse de cada grupo. Por meio de dinâmicas interativas e participativas, os temas eram identificados e elencados pelo grupo e nele.

A dinâmica dos jovens nos grupos apresentou-se com as características próprias dessa faixa etária: euforia, alheamento, mudanças bruscas de humor, exigências de atenção por parte dos facilitadores, etc. Por conta disso, houve muitas mudanças no planejamento das oficinas, o que exigiu da equipe 
constante atenção aos processos que se desenrolavam e, acima de tudo, 'jogo de cintura' para o replanejamento de atividades e temas.

Diante de uma ampla gama de possibilidades, tivemos de priorizar e imbricar alguns temas que se mostraram mais relevantes. Entretanto, algumas questões centrais, como a identidade de gênero, por exemplo, permearam toda a trajetória do desenvolvimento das oficinas, inclusive os debates sobre violência, saúde, família, cidadania, etc.

Alguns temas que assumiram maior relevância para os jovens e que apontaram questões de pesquisa, posteriormente investigadas e aprofundadas, ${ }^{8}$ estão apresentados a seguir.

\section{Gênero, saúde sexual e reprodutiva}

No decorrer do trabalho, moças e rapazes tiveram a oportunidade de confrontar idéias e (pre)conceitos inerentes às culturas de gênero. A experiência de reflexão em grupos mistos mostrou-se um terreno fértil para emergirem

${ }^{8}$ Encontra-se em fase de conclusão uma pesquisa qualitativa que comparou jovens participantes e não participantes de projetos sociais em relação aos seguintes temas, identificados por meio dos processos ocorridos nos GRG: identidade de gênero, família, violência, drogas, religião, cidadania $e$ política. diálogos, tensões, conflitos, controvérsias e, também, consensos. Desta forma, a metodologia promoveu reflexão sobre os estereótipos de gênero que permeiam as relações no cotidiano, estabeleceu sua relação com as condutas sexuais $e$ reprodutivas dos jovens e relacionou a discussão sobre as identidades de gênero com as outras dimensões de vida, na perspectiva transversal.

Na dinâmica dos grupos, pudemos observar que, além da participação masculina ser mais restrita, o discurso dos rapazes tendia a ser abafado pela veemência com que as moças se colocavam em relação às diversas questões debatidas. Percebemos que a ideologia do gênero masculino, forjada, por um lado, na representação do homem provedor e autoridade no âmbito da família $e$, por outro, identificada com o exercício do poder por meio da força na esfera pública, embora ainda exerça grande influência no imaginário masculino, tende a ser confrontada com uma nova realidade, onde a mulher vem ocupando espaços que, até então, não lhe cabiam. Na fala de uma jovem:

Hoje em dia, são as mulheres que seguram a onda da família. Vocês, homens, não dão conta nem de vocês mesmos.

Diante desta contradição, não podemos deixar de perguntar: como se sentem os rapazes que vivem nesses contextos? Dadas as dificuldades de emprego dos jovens, não estará esse 'enfraquecimento' das possibilidades de ser o 'provedor' impulsionando a atração pelo outro 'poder masculino' e influindo na massiva adesão desses jovens aos grupos armados? Fica aqui registrada a questão para futuras investigações.

Por outro lado, no âmbito das oficinas, enquanto as moças denotaram uma vivacidade surpreendente diante dos desafios de um difícil cotidiano, os rapazes freqüentemente pareciam mais acuados e inseguros diante da nova situação que se apresentava e para a qual não foram preparados. Não se pode deixar de considerar que esses rapazes sofrem uma constante ameaça à sua integridade física e, em muitos momentos, à própria vida, em decorrência da constante violência do tráfico e das forças policiais, o que certamente repercute sobre uma identidade masculina ainda em processo de formação. 
Como proposto, gênero foi uma questão trazida e debatida nos mais diversos momentos dos grupos. O mesmo ocorreu com a saúde reprodutiva. Contudo, foram realizadas oficinas específicas que facilitaram o relato de experiências pessoais e potencializaram novas reflexões em grupo, como a dinâmica do 'Crachá de Gênero', que permitiu traçar o perfil dos estereótipos masculino/feminino para, em seguida, problematizá-lo; $e$ a construção do painel "O Mundo do Homem - O Mundo da Mulher", que abriu intensos debates sobre as relações de gênero.

O emocionado depoimento abaixo, de uma jovem participante de um dos grupos, indica a relevância tanto do processo reflexivo para o trabalho educativo quanto de uma escuta acolhedora e compreensiva que possa representar um "porto seguro" nos momentos de turbulências da vida:

\begin{abstract}
Naquela hora, durante o exercício de sensibilização, que você mandou levar a mão ao coração, alguma coisa mexeu diferente dentro de mim. Veio na minha mente aquelas meninas que passam grávidas na minha porta. Eu lembro como era a minha cabeça quando fiquei grávida. Eu não sabia pensar. Só sentir. Era muita confusão. Eu sabia de tudo, mas o problema era as coisas que eu sentia ( emoções ), que eu não entendia, não sabia nem como explicar... e como é que eu ia falar disso? Falar disso com quem? Agora, quando a gente faz reflexão aqui no grupo, que a gente fala e escuta as histórias dos outros, é que eu começo a entender melhor como eu era antes e posso entender como essas meninas pensam, $e$ aí aumenta a minha vontade de fazer alguma coisa.
\end{abstract}

Nessa fala, percebe-se quanto o processo de autoconhecimento e reflexão, metodologicamente falando, é um processo social, no sentido da importância fundamental de se estabelecerem cumplicidades e empatia com o 'outro', tradicionalmente tomado apenas como objeto passivo da ação educativa. A nosso ver, essa constatação reforça a propriedade dos GRG, quando se tem como objetivo gerar transformações.

A leitura do livro de depoimentos "Palavra de Homem" (Lopes et al., 2001), gerado por nosso projeto de pesquisa-ação anterior, levantou o interesse e a curiosidade dos participantes em relação às posturas diferenciadas de homens e mulheres, particularmente no que diz respeito aos cuidados com a saúde. A partir daí, vários temas foram eleitos para reflexão e debate, tais como: paternidade e filiação, sexualidade, relações de gênero e violência doméstica, entre outros.

Vale a pena destacar o processo reflexivo desencadeado pelas dramatizações, criadas e encenadas pelos participantes de um dos grupos, abordando o tema saúde e problematizando as distintas formas como esta é percebida por homens e mulheres. Em uma das dramatizações, foi representada uma situação onde um homem morria em função de sua própria resistência em aceitar que estava doente e precisava procurar tratamento médico. Vale ressaltar que a encenação não descuidou da crítica sobre a precariedade de atendimento nos serviços públicos de saúde, particularmente aqueles voltados para a assistência aos homens. O tocante dessa "encenação" foi a revelação de que a cena montada baseou-se em uma situação real, tal como vivida pelo pai de uma 
participante. A apresentação foi seguida de um caloroso debate., em que os jovens puderam perceber a existência de lacunas no que se refere aos programas de saúde voltados para a população masculina:

Tem muito mais revista com informações sobre saúde pra mulher do que pra homem.

Os homens parecem que tem vergonha de dizer que está doente.

Eu mesmo nunca procurei o Posto de Saúde. Só tem mulher lá.

É mais fácil pra mulher falar de suas dores.

Em outro grupo, uma dramatização explorou as dificuldades encontradas pelas mulheres para negociar com seus parceiros o uso da camisinha. Nessa encenação, as mulheres identificam a sedução como o único argumento convincente e não ameaçador. Porém, constatam que, na maioria dos casos, as mulheres terminam por submeter-se à vontade masculina. Na discussão que se seguiu à dramatização, ficou claro para o grupo que, mesmo se tratando de uma encenação, ainda é difícil para as mulheres darem um novo rumo à prevenção de DST/Aids de forma a garantir sua saúde. Houve consenso, entre rapazes e moças, de que a responsabilidade pela prevenção é de ambas as partes, embora se perceba que, na prática, isso (ainda) não ocorre, ficando a responsabilidade maior ao encargo das mulheres.

A gente tenta, mas os caras não aceitam. Sei de muitas meninas que transam sem camisinha pra não perder o namorado.

Às vezes rola o clima, a menina dá mole, e nem dá tempo de pensar em mais nada. Vai assim mesmo...

Acho que todo mundo sabe da coisa, mais isso não garante nada, porque a gente sempre acha que, com a gente, não vai acontecer nada.

Se eu disser prá ele usar, ele vai achar que eu ando aprontando...

Não é só usar também, tem que ler as instruções, senão arrebenta. Comigo já aconteceu, e eu quase pirei.

Camisinha custa dinheiro, e tem cara que fica sem graça de pedir no Posto de Saúde.

Nesses debates, a equipe resgatou e pontuou as conquistas alcançadas pelo movimento de mulheres, particularmente no que diz respeito às políticas públicas de saúde. Porém, não deixou de confrontar as conquistas formais, como aquelas consubstanciadas no Programa de Assistência Integral à Saúde da Mulher, com a realidade da assistência pública à saúde das mulheres, ainda muito distante do ideal. 
Portanto, nas calorosas discussões sobre as identidades de gênero e suas relações com o cuidado com a saúde, particularmente a saúde reprodutiva, evidenciamos quanto o referencial transversal proposto permitiu a esses jovens não só problematizarem as identidades de gênero hegemônicas, como fazerem entrecruzamentos críticos entre as políticas de saúde e as várias dimensões de identidades sociais, tanto no plano coletivo quanto no individual, o que inclui a subjetividade.

\section{Família}

Segundo Vasconcelos (1999), para a classe trabalhadora, a família representa um espaço de conformismo e adaptação, mas também de resistência a esta sociedade exploradora e opressora. Contraditoriamente, pode manter e reforçar a subordinação feminina ao mesmo tempo em que procura proteger as mulheres e crianças da violência social. Embora reproduza a dominação masculina, é também um espaço de resistência à subordinação dos homens ao mundo do trabalho. Assegura a reprodução da força de trabalho para o capital, mas garante a sobrevivência material e simbólica da própria classe trabalhadora. É não só núcleo de tensões e conflitos, mas o lugar onde se obtém prazer, afeto e reconhecimento.

Como prevíamos, este tema esteve presente em todos os grupos de forma bastante significativa, na medida em que a maior parte dos integrantes ainda está agregada ao seu núcleo familiar de origem; e que a família continua a representar a principal e, às vezes, a única rede de apoio social para esses jovens.

$O$ diferencial encontrado ficou por conta das diferentes fases de vida dos jovens nos diversos grupos. Alguns participantes do primeiro grupo, todos muito jovens, criticaram e responsabilizaram as famílias, e também o poder público, pela falta de apoio e estímulo aos jovens. Por outro lado, no segundo grupo, onde vários participantes já haviam constituído suas próprias famílias, esta foi percebida como um espaço de grande importância para apoio $e$ manutenção do equilíbrio dos indivíduos.

Após o processo de reflexão, porém, o primeiro grupo passou a relacionar os problemas vivenciados pelas famílias com os problemas que atingem a coletividade e com os quais lidam diariamente, seja na condição de multiplicadores, seja na condição de membros de uma família. Esta visão crítica ficou patente quando, ao refletirem sobre as condições de vida na Maré sob a ótica familiar, os primeiros questionamentos de ordem política começaram a surgir:

Percebo que aqui as crianças, na maioria das vezes, crescem muito rápido por causa da responsabilidade que são obrigadas a assumir, ou então porque se envolvem com coisas erradas.

Precisamos de mais projetos [sociais] pra beneficiar [também] os pais.

Eu estou muito chateada, porque uma das meninas que eu ajudava contraiu AIDS. Estou me sentindo culpada, pois foi justamente no período que minha mãe me proibiu de distribuir as camisinhas para um grupo de meninas prostitutas que eu estava atendendo. 
Ih !!! Se ele tivesse que depender da família, estava perdido. O pai dele é alcoólatra e a mãe dele cheira cocaína. Ele é quem cuida dos irmãos. Faz comida e tudo na casa dele.

Esses depoimentos sinalizam quanto as inúmeras carências às quais esses jovens estão submetidos refletem-se sobre suas famílias e se tornam obstáculos ao cuidado com a saúde, inclusive a reprodutiva. Podemos, também, perceber os entrelaçamentos entre situações estigmatizadas pela sociedade - tal como a prostituição $e$ a adicção ao álcool $e$ às drogas - $e$ o cuidado com a saúde. Ao problematizarem essas questões, os jovens estão potencialmente encontrando caminhos para superá-las, tanto no plano individual quanto em suas atuações como agentes de transformação.

Enquanto isso, os participantes do segundo grupo, em que alguns já eram provedores familiares, identificaram a família e a comunidade como células matrizes da construção da identidade social e cidadania. Um lugar no mundo onde as pessoas, mesmo quando em processo de desfiliação (Castel, 1994), podem encontrar reconhecimento, apoio e estímulo para não desanimarem ou desistirem frente a tantas adversidades:

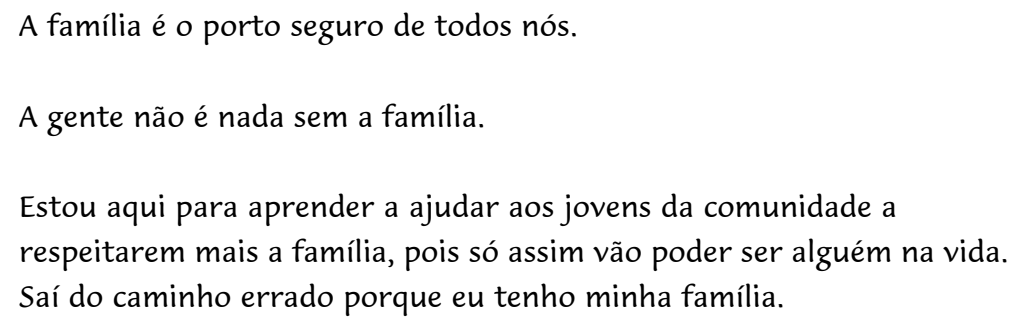

Tornou-se visível a importância do sentimento de pertencimento ao grupo familiar na constituição de identidade, já que este possibilita o (re)conhecimento do valor de cada um. As falas explicitaram quanto o pertencimento a um grupo designa aos indivíduos, particularmente os jovens, uma função, um lugar e um sentido de vida, tal como pontuado por Vasconcelos (1999, p.9):
A vida familiar constitui um espaço importante para a elaboração de um destino comum, para o amadurecimento de um saber sobre o espaço, o tempo, a memória, para a transmissão de conhecimentos e informações $e$ para a compensação da pouca escolarização com outros aprendizados transmitidos oralmente e por contato.

A importância do pertencimento, que também pode ser visto por seu enfoque negativo, possibilita explicar e justificar a adesão às chamadas "gangues" do tráfico de drogas que, mesmo por meio do antagonismo, proporcionam a gratificação pela inclusão numa comunidade de pares. No contexto de falta de oportunidades a que está submetida grande parte dos jovens brasileiros, é possível compreender como, às vezes, ser bandido é melhor que ser ninguém, quando não se encontra espaço propício para a construção da identidade, inclusive a de gênero. 
Assim, a discussão desta temática e as questões que emergiram dos processos reflexivos nos permitem relacionar a construção das identidades de gênero às relações familiares $e$ ao contexto social mais amplo, onde o sentimento de pertencimento se mostra de extrema relevância.

\section{Identidade e cidadania}

Morar na Maré traz para os jovens "mareenses" um profundo sentimento de desconforto - um misto de vergonha, raiva e revolta - em decorrência do forte preconceito que existe em relação aos moradores de favelas. Na maioria das fichas de identificação, ${ }^{9}$ os jovens colocaram como endereço o bairro Bonsucesso, sem mencionar a Maré. Como nos confirmaram depois, esta estratégia é freqüentemente utilizada como forma de se protegerem do preconceito e da discriminação.

É evidente que tal condição afeta negativamente sua auto-estima e é tão relevante que, como veremos, acompanhará e norteará todas as discussões seguintes. Mesmo assim, puderam perceber e falar da Maré, comunidade onde nasceram e se criaram, com positividade, carinho e esperança de que as coisas possam mudar.

Existe beleza na Maré assim como existe muito preconceito lá de fora. Precisamos ter outra visão da favela.

O povo aqui é muito unido. Mesmo assim, deveria haver mais união $e$ prevenção.

Fico triste com todas essas coisas que acontecem aqui. Aqui é muito bom, as pessoas são legais. Pena é essa bandidagem.

${ }^{9}$ Os participantes preenchiam um "retrato inicial", fornecendo alguns dados

sociodemográficos e familiares $e$

respondendo a

algumas perguntas relacionadas à saúde $e$ às suas motivações para participar do projeto.

$\mathrm{Na}$ criação de um painel coletivo sobre o tema "O que eu imagino de bom para a Maré", suas aspirações por direitos de cidadania - da limpeza urbana à liberdade de circulação - puderam se expressar:

Uma Maré mais limpa.

Não acontece justiça para todos aqui na Maré.

Queria que parassem os conflitos entre gangues que afastam os jovens dos diferentes lugares.

Gostaria de ver mais liberdade para as pessoas, liberdade de ir e vir sem os conflitos que existem no lugar onde vivemos. Isso iria melhorar a ação dos projetos.

Na discussão desta temática, emergiu, entre os jovens, a consciência de que os rapazes são os mais afetados por essa situação, tanto na adesão aos grupos criminosos quanto no cerceamento à sua liberdade de circulação e o alto risco de sofrerem violências (do narcotráfico e policial). Novamente, 
pudemos relacionar as identidades de gênero às questões sociais mais amplas, indo além da tradicional $e$ abstrata constatação do 'poder' masculino, para observar como as condições sociais concretas vão condicionar as possibilidades de esses jovens se realizarem enquanto cidadãos, homens e mulheres.

\section{Educação, trabalho e auto-realização}

Desde os primeiros encontros, os jovens mostraram que, nem sempre, o desejo de crescimento no sentido de obter uma vida plena e digna é fácil de ser atingido para quem nasce e vive na Maré. As críticas referentes à falta de vagas na rede oficial de ensino e à própria qualidade do ensino oferecido revelam que o ensino público pouco contribui para lhes infundir qualquer esperança de alcançar a universidade e, por meio dela, uma melhor qualificação profissional.

No que diz respeito à inserção no mercado de trabalho, a questão não é menos complexa e difícil para os jovens. As ofertas de emprego são mínimas e, em sua maioria, exigem um nível de capacitação que a maioria deles ainda não pôde obter. De um modo geral, a tendência é se contentarem com subempregos que não lhes garantem mudanças significativas no padrão de vida de suas famílias. A questão financeira é recorrente em todas as discussões, expressandose por meio de sentimentos de ansiedade e preocupação, com o presente e o futuro. Alguns jovens, inclusive, são pressionados pela família a deixarem o projeto social de que participam para buscarem trabalho remunerado, o que explicita o conflito entre o desejo de capacitação e a urgência da sobrevivência:

Minha mãe quer que eu saia do projeto para ir trabalhar.

Nas várias reflexões sobre o tema, a discussão sobre a falta de oportunidades de emprego remetia os jovens para o desejo de ampliar seus conhecimentos $e$, também, para suas aspirações por uma melhor qualidade de vida, o que pressupõe o acesso ao lazer, aos esportes e à cultura, vistos como caminhos para o crescimento pessoal:

Acho que deveria haver um museu aqui na Maré.

Mais informática e informação para todos.

Deveria haver campeonatos ou incentivos para podermos mostrar nossa arte.

Mais oportunidades de estudo para os jovens.

Portanto, a discussão destes temas evidenciou quanto as barreiras de classe social, certamente entrelaçadas às raciais, impedem o desenvolvimento de aptidões e talentos de rapazes e moças que, como todo jovem, têm projetos $e$ sonhos para o futuro.

\section{Inserção em redes sociais}

Valendo-se das vivências nos grupos, e em consonância com a perspectiva de ação, de engajamento ativo, os jovens foram estimulados a formarem e/ou se 
integrarem em redes sociais de jovens que se organizam para reivindicar políticas públicas para a juventude, tanto no nível local quanto em uma perspectiva mais ampla, em recente movimento social da juventude brasileira. Com base no entendimento de que melhorias no contexto de vida dos jovens brasileiros só ocorrerão se alavancadas por políticas públicas abrangentes e universais e com a participação massiva e organizada dos próprios jovens, trabalhamos, desde o início do projeto, na perspectiva de estimulá-los a se inserirem nas redes e nos movimentos sociais já existentes ou em formação.

Neste sentido, estimulamos os participantes a descobrirem como essas redes - formais e informais - funcionam, como podem potencializar o desenvolvimento de capacidades individuais e coletivas e, ainda, como cada um pode trabalhar sua própria rede de influências no sentido da multiplicação e construção de novas propostas coletivas de ação.

No decorrer do projeto, com o engajamento dos jovens nessas redes, pretendemos contribuir para o fortalecimento de movimentos mais amplos que estão, atualmente, proporcionando encontros, ações e reflexões de/para/ com os jovens. Esses movimentos caracterizam-se pela pluralidade $e$ diversidade de seus integrantes: são profissionais da saúde e educação, estudantes, lideranças comunitárias, jovens, adultos, mulheres e homens, negros e brancos, religiosos ou não, e estão se materializando como redes sociais. Duas redes que a equipe do projeto apoiou desde sua formação inicial foram a Rede Jovens em Movimento, de âmbito estadual, e a Rede Maré Jovem, de âmbito local ${ }^{10}$.

Ambas as redes se organizam e buscam se articular com instâncias do poder público e com movimentos mais amplos de juventudes ora em curso no país. Particularmente, a Rede Maré Jovem tem corajosamente levantado a questão das 'fronteiras invisíveis' na Maré, denunciando os limites territoriais impostos por diferentes facções do crime organizado que impedem a livre circulação dos jovens, especialmente dos rapazes. Nesta questão, assim como nos GRG, ficam evidenciadas as contribuições e a força desses jovens, rapazes e moças, para a ação política coletiva de enfrentamento do grave problema de segurança pública que a cidade e o país enfrentam.

Desta forma, pudemos evidenciar que, além da luta pela conquista dos direitos reprodutivos, é preciso incluir, para a maioria da juventude brasileira, a reivindicação de direitos humanos elementares, tais como o direito à vida e à liberdade de ir e vir.

\section{Considerações finais}

A proposta central de nosso trabalho foi a formação de grupos de reflexãoação de jovens que vivem no Complexo da Maré com o objetivo de estimular o autoconhecimento, a auto-estima, a valorização do saber prático, a criatividade e a construção de projetos coletivos comprometidos com a luta por igualdade e justiça social.

O processo reflexivo de gênero em grupos de jovens, promovido por meio de uma metodologia participativa que incorpora a expressão artística nos processos de reflexão-ação, confirmou-se como ferramenta valiosa,
${ }^{10}$ A primeira articulouse no Rio de Janeiro a partir do II Fórum Social Mundial, realizado em Porto Alegre, RS, em 2002. A segunda, de âmbito local, nasceu dos encontros realizados pela rede Jovens em Movimento. 
11 Trecho da música "O que é, o que é", de Luiz Gonzaga Jr. permitindo despertar o interesse e promover a sensibilização dos participantes para a reflexão e o debate sobre suas questões significativas. A perspectiva da ação - e da multiplicação - implícita na pesquisa-ação, mobilizou esses jovens, desde o início, para um olhar crítico e um engajamento coletivo, o que se revelou por intermédio da elaboração de projetos conjuntos para a atuação no âmbito comunitário. Pensar a Maré e descobrir sua positividade em meio a tantos e graves problemas representou a possibilidade de re-significar um espaço e uma cultura que têm sido sistematicamente desqualificados e caracterizados, pelos "de fora", como "perigosos".

Neste sentido, e na contramão de muitas entidades que patrocinam projetos neste campo, re-afirmamos a importância de não se isolarem os temas de gênero, de sexualidade e saúde reprodutiva das questões de vida mais amplas, sob risco de reproduzirmos modelos de intervenção que pretendem, em última instância, o controle sobre a reprodução social. Como os jovens da Maré mostraram, a vida não é compartimentada em dimensões $e$ segmentos separados, mas um processo que se realiza em determinadas condições que enredam, como numa teia, as várias dimensões constitutivas dos sujeitos sociais, material e simbolicamente. Se almejamos transformá-la ("a vida devia ser bem melhor.... e será!" 11 ), devemos investir no fortalecimento dos elos da teia (e não na sua segmentação).

No nível dos grupos, confirmamos a importância de uma "escuta" acolhedora, compreensiva e solidária, o que requer dos facilitadores da equipe uma postura aberta e flexível, que crie condições para que as difíceis $e$ candentes questões trazidas pelos jovens possam se expressar sem medo de censura e/ou rejeição, e para que sua auto-estima e dignidade possam ser reconhecidas e fortalecidas.

Embora não tendo previsto qualquer tipo de apoio financeiro aos jovens participantes, pudemos comprovar que estes consideraram essa experiência, adquirida em um intensivo processo de exercício da capacidade reflexiva, como um ganho considerável para suas vidas pessoais e coletivas.

Concluímos o trabalho com a convicção de que as instituições públicas de ensino e pesquisa têm importante papel a desempenhar no desenvolvimento de conhecimentos críticos e metodologias que possam subsidiar a elaboração de políticas públicas de saúde e educação para a população brasileira, tal como preconizado no Plano Nacional de Extensão Universitária (PNE, 2001). Esta concepção propõe nosso engajamento nas "discussões, elaboração e execução de políticas públicas que tenham a cidadania e o cidadão como suas principais referências", preferencialmente adotando e desenvolvendo "metodologias que propiciem a participação das populações na condição de sujeitos, e não de meros expectadores" (PNE, 2001, p.4, 5, grifo nosso).

Em função da magnitude e abrangência dos problemas vividos pela população jovem brasileira, advogamos a necessidade inadiável de promoção, pelo Estado e as várias esferas governamentais, de políticas públicas universais, abrangentes, articuladas entre si e com uma perspectiva geracional (Castro et al., 2001), o que pressupõe o envolvimento e a participação ativa dos jovens em todos os momentos do processo, da elaboração à implantação, monitoração $e$ avaliação de programas $e$ 
propostas de ação.

Como evidenciamos, nossos jovens detêm um imenso potencial criativo, uma energia transbordante e a crença inquebrantável de que "um outro mundo é possível", ${ }^{12}$ com igualdade e justiça social.

\section{Referências}

CASTEL, R. Da indigência à exclusão, a desfiliação - precariedade do trabalho e vulnerabilidade relacional. In: LANCETTI, A. (Org.). Saúde e loucura 4. São Paulo: Hucitec, 1994. p.21-48.

CASTRO, M.G.; ABRAMOVAY, M.; RUA, E. G.; ANDRADE, E.R. (Orgs.). Cultivando vida, desarmando violências: experiências em educação, cultura, lazer, esporte e cidadania com jovens em situação de pobreza. Brasília: Unesco, Brasil Telecom, Fundação Kellogg, BID, 2001.

CONNELL, R.W. Políticas da masculinidade. Educ. Real., v.20, n.2, p.185-206, 1995.

FREIRE, P. Pedagogia da autonomia: saberes necessários à prática educativa. 19.ed. São Paulo: Paz e Terra, 1996.

. Criando métodos de pesquisa alternativa. In: BRANDÃO, C.R. (Org.). Pesquisa participante. São Paulo: Brasiliense, 1981. p.34-41.

GIFFIN, K. Produção do conhecimento em um mundo 'problemático': contribuições do feminismo dialético e relacional. Ver. Estud. Fem., v.14, n.3, p.635-4, 2006.

. Pobreza, desigualdade e equidade em saúde: considerações a partir de uma perspectiva de gênero transversal. Cad. Saúde Pública, v.18 supl, p.103-12, 2002.

. Corpo e conhecimento na saúde sexual: uma visão sociológica. In: GIFFIN, K.M.; COSTA, S.H.

(Orgs.). Questões da saúde reprodutiva. Rio de Janeiro: Fiocruz, 1999. p.79-91.

Estudos de gênero e saúde coletiva: teoria e prática. Saúde em Debate, n.46, p.29-33, 1995.

HOLLANDA, E. Práticas alternativas de pesquisa: alguns questionamentos sobre as potencialidades e limites da pesquisa-ação e pesquisa participante. In: VALLA, V.V.; STOTZ, E.N. (Orgs.). Participação popular, educação e saúde: teoria e prática. Rio de Janeiro: Relume Dumará, 1993. p.24-51.

KERGOAT, D. Relações sociais de sexo e divisão sexual do trabalho. In: LOPES, M.J.; MEYER, D.; WALDOW, V.. (Orgs.). Gênero e saúde. Porto Alegre: Artes Médicas, 1996. p.19-28.

LOPES, A.; AMORIM, A.; COUTINHO, A.M.; COSTA, C.; COSTA, C.S.; OLIVEIRA, G. J.; GARCIA, J.L.; BARROS, J.C.C.; SILVA, J.L.; AGUIAR, J.O.; MOREIRA, L.F.; BARBOSA, M.R.G.; STROZENBERG, P.D.; SOUZA, R.F.; ALVES, S.C.; SILVA, S.J.A; GONÇALVES, V.A.B.Q.; CORREIA, W.S. Palavra de homem. Rio de Janeiro: NESC-UFRJ/ENSP-FIOCRUZ, 2001.

PLANO NACIONAL DE EXTENSÃO UNIVERSITÁRIA. PNE. Fórum de Pró-Reitores de Extensão das Universidades Públicas Brasileiras e Secretaria de Educação Superior do Ministério da Educação e do Desporto - SESu / MEC. 2001. Disponível em: <http://www.sr5.ufrj.br/documentos/pne.doc>. Acesso em: 6 out. 2004.

REASON, P. Three approaches to qualitative inquiry. In: DENZIN, N. (Org.) Handbook of qualitative research. Thousand Oaks: Sage, 1994. p.324-39.

SAFFIOTI, H.I.B. Rearticulando gênero e classe social. In: COSTA, A.O.; BRUSCHINI, C. (Orgs.). Uma
12 Lema do Fórum Social Mundial, encontro anual que congrega militantes de todo o mundo engajados na luta pela justiça social. Realizase desde 2000. 
questão de gênero. Rio de Janeiro/São Paulo: Rosa dos Tempos/Fundação Carlos Chagas, 1992. p.183-216.

SIMÕES BARBOSA, R.H. Mulheres, reprodução e aids: as tramas da ideologia na assistência à saúde de gestantes Hiv-positivas. 2001. Tese (Doutorado) - Escola Nacional de Saúde Pública, Fundação Oswaldo Cruz, Rio de Janeiro.

. Educação e saúde reprodutiva: análise preliminar de uma experiência numa comunidade favelada do Rio de Janeiro. In: SILVA, D.P.M. (Org.). Sexualidade em diferentes enfoques: uma experiência de capacitação no campo da saúde reprodutiva. Niterói: PEGGE/UERJ, 2001a. p.123-31.

SIMÕES BARBOSA, R.H.; GIFFIN, K. Juventude, saúde e cidadania: uma pesquisa-ação com jovens da Maré. Cad. Saúde Colet., v.13, n.3, p.649-72, 2005.

VALLADARES, D.; SANCHEZ, S.; GIFFIN, K. Mulheres, participação e saúde. Rio de Janeiro: FLACSO/ CNDM/UNICEF, 1987.

VASCONCELOS, E.M. A priorização da família nas políticas de saúde. Saúde em Debate, v.23, n.53, p.6-19, 1999.

BARBOSA, R. S.; GIFFIN, K. Género, salud reproductiva y vida cotidiana en una experiencia de pesquisa-acción con jóvenes que viven en Maré, Río de Janeiro. Interface - Comunic., Saúde, Educ., v.11, n.23, p.549-567, set/dez 2007.

Este artículo presenta una conceptuación de la pesquisa-acción que articula la pedagogía de Paulo Freire y la propuesta reflexiva y práctica del movimiento de mujeres. Se propone contribuir para ampliar la comprensión de los problemas que afectan a la juventud brasileña a partir de cuestiones de vida y salud vivenciadas por jóvenes - chicos y chicas - que habitan en el Complejo de Maré, área de favelas de la ciudad de Rio de Janeiro. Estas cuestiones se captaron a través de un proyecto que reunió a jóvenes en grupos de reflexión-acción, adoptando como temas generadores la identidad de género, la sexualidad y la salud reproductiva; temas que se conectan gradualmente con otras cuestiones significativas que emergían de las dimensiones socio-culturales y políticas más amplias que afectan a la vida de los jóvenes, particularmente de los que viven en contextos de pobreza, violencia y exclusión de derechos. Se buscó consolidar, conceptual y empíricamente, el foco en la línea transversal del género en la clase social y el paradigma de conocimiento que legitima un nuevo sujeto de conocimiento comprometido con una acción transformadora.

PALABRAS CLAVE: Juventud. Salud reproductiva. Investigación-acción. Ciudadanía. 


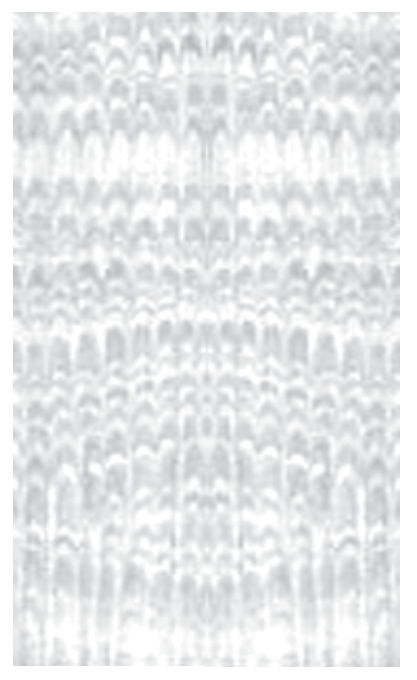

